Article

\title{
Turnover among foreign nurses in Saudi Arabia
}

\author{
Nashi Masnad Alreshidi, ${ }^{1}$ Laila Mohammad Alrashidi, ${ }^{2}$ Abdulrahman Nayir Alanazi, ${ }^{3}$ \\ Eida Habeeb Alshammeri ${ }^{4}$
}

${ }^{1}$ Continuing Nursing Education Director, Nursing Administration in Hail Region, Hail City; ${ }^{2}$ Head Nurse, Antenatal Department in Maternity and Child Hospital, Hail City; ${ }^{3}$ Quality and Patient Safety Director at Eradah Complex for Mental Health, Arar City; ${ }^{4}$ Continuing Nursing Education Department. Maternity and Child Hospital, Hail City, Saudi Arabia

\begin{abstract}
Background: Globally, nursing turnover has become a contemporary concern that significantly influences the financial proficiency of healthcare systems. Not only costs, but healthcare accessibility and quality also reverberate the consequence of the phenomenon.

Design and methods: The study explores the factors that attribute to turnover among foreign registered nurses working in Saudi Arabia. A quantitative-based cross-sectional descriptive study design that uses survey data to make statistical inferences about foreign nurse turnover in Saudi Arabia, was conducted to ascertain factors influencing the termination of foreign nurses working with the Ministry of Health (MOH) hospitals.

Results: Factors influencing turnover were categorized into 9 dimensions, professional growth and development, leadership style, management, wage and benefits, workload, interpersonal relationship, housing facilities and services, hospital facilities and intent to stay and turn-over intention, of which the professional growth (4.1 \pm 0.7$)$ and development had the highest mean agreement scores $(4.0 \pm 1.1)$, whereas housing $(2.3 \pm 1.3)$ and hospital facilities $(2.1 \pm 1.0)$ showed the lowest mean scores.

Conclusions: Wage benefits and workload factors were found to be the most significant causes of expatriate nursing turnover, closely followed by inadequate housing and hospital facilities. Recommendations from nursing staff on how to improve retention were also noted.
\end{abstract}

\section{Introduction}

Turnover is a challenging issue in terms of high quality, affordable healthcare. Globally, nursing turnover has become a contemporary concern that significantly influences the financial proficiency of healthcare systems. ${ }^{1,2}$ Not only costs, but health- care accessibility and quality also reverberate/compounds the consequence of the phenomenon..$^{1-3}$ The annual nursing turnover rates in Australia, Canada and the United States are around 15\%, 20\% and $27 \%$, respectively. ${ }^{4}$ The estimated turnover in Jordan, is relatively more at $32 \% .{ }^{5}$ Turnover rates appear to be superlative amongst recent nursing graduates and new recruits. ${ }^{6}$ This in turn, negatively impacts the staff to client ratios and healthcare outcomes. In the last five years, only two relevant research articles, ${ }^{7,8}$ have been found related to foreign nurses' turnover in Saudi. Aljohani et al. indicated that the common cause of turnover for Filipino nurses in the Saudi Arabian Ministry of Health (MOH) hospitals to be related to low salary, ${ }^{7} 18.3 \%$ of the recruited participate indicate the low salary and low nursing patient ratio to be the most significant factor in Filipino nursing turnover in Saudi Arabian hospitals, until now the sample not representative the Filipino nurses population. ${ }^{7}$ Findings indicated that financial incentives, indeed are a primary driving force for those working internationally in healthcare organizations. ${ }^{9}$ The second study ended in low tertiary care sites in Saudi Arabia randomly selected with a representative sample of 364 nurses, the majority of foreigners at a rate of $97 \%$; the study indicated the low satisfaction of nurses of their quality of nursing work life and high turnover intention. ${ }^{8}$ Existing studies have recorded significant facts determining the common reasons for turnover, and high lightening the areas of improvement to develop strategies that aim to improve retention. However, there are some limitations to the first study requiring further investigation. The primary limitation of Aljohani et al.'s study was the convenience sampling, which remains a weak basis to generalize a specific group of expatriates. ${ }^{7}$ Convenience sample limits the generalization of specific study findings to the targeted papulation. Hence, this study desire to explore further issues associated with turnover among the foreign nursing staff working in Saudi Arabia, not only to improve staff nurses' retention strategies, but also to establish factors related to turnover intention to address potential turnover behaviors.

Significance for public health

The nursing workforce is considered the backbone of the healthcare delivery system. In Saudi Arabia, foreign nurses employ a large percentage of human resources required in healthcare institutions. Thus, foreign nurses' increasing turnover rates remain a significant problem affecting healthcare institutions across the country. Staff turnover rate is the prime source of workforce shortage that impacts the operational domain, thereby negatively affecting productivity and revenues. The high turnover rates negatively impact organizational in quality of care and resources to recruit and train new staff, prompts many scholars to investigate possible causes, and to develop a comprehensive staff retention strategies. Determining associated factors on staff turn-over, provides insights that will guide facility policy makers and stakeholders to keep pace with the demand of public health system. 


\section{Literature review}

The nursing turnover are discussed through the view of the previously conducted studies and literature. There are several essential aspects in the general discussion of nurse's turnover. Nursing reworded the largest component of the healthcare workforce. ${ }^{10,11}$ The nursing contributions considered fundamental to healthcare, particularly in view of the escalating aged population and the burden of chronic non-communicable diseases considering the chronic imbalance between nurses and physicians. ${ }^{1,10}$ With respect to human resource management, challenges are compounded. Investment scarcity ${ }^{12}$ and growing indifference to the profession $^{13}$ are two of the critical issues associated with the scarcity of nurses. Additionally, psychosocial strain ${ }^{14,15}$ and high turnover ${ }^{12-}$ 16 are strongly related to intentions to leave the nursing profession. ${ }^{17,18}$ Many studies have identified the intention to quit nursing as a predictor of the ultimate decision. ${ }^{1-19}$ The Nurses' Early Exit Study (NEXT), ${ }^{20}$ found that ultimately, the decision to leave nursing is mostly taken within 6 months of actually doing so. It also been reported by Hasselhorn et al. ${ }^{20}$ that about $80 \%$ of nurses who left the profession began seriously considering the move within the previous year. Nurses are a very diverse group of professionals, culture and alternative employment opportunities can have an impact on their intention to leave, the mindset that strengthened the idea, was "intention to leave" has often been probed, particularly using quantitative methods to determine associations with many variables that can influence nursing resolution to leave. $8,7,21$ Occupational factors related to the "intention to leave" change the profession include hospital work environment, poor support from supervisors, lack of importance of the work, conflicting roles, and lack thereof in development opportunities. ${ }^{14-}$ 22 Nurses" "intention to leave" in the professional capacity has been ascribed to psychosocial job strain ascertained by "demandcontrol-support" (DCS) ${ }^{23}$ and "effort-reward imbalance" (ERI) ${ }^{24}$ models. In this regard, the "intention to leave" is a phenomenon concomitant with the healthcare organization and occupational environment issues. Further studies have shown that the "intention to leave" can occur in the form of a causal nexus, with many nurses leaving first their unit, then their hospital, and ultimately the profession. ${ }^{25,26}$ To present, nursing staff, work stress, and job satisfaction remain two significant areas of interest for researchers worldwide because of the continuum in shortage of nurses and high turnover. Earlier studies have suggested that work stress in healthcare providers is a dominant factor, particularly in nurses. Being front-line staff, work overload threatens physical and mental health. ${ }^{27,28}$ Markedly, the special working environments and work configuration impacts the immense rates of work stress that nurse's experience when compared to other professions. Nursing work stress is a pandemic, globally spanning $9.20-68.0 \%$ of nurses. ${ }^{2}$.Withen emergency nurses greater than $80 \%$ of nurses expressed moderate or even high levels of burnout and compassion fatigue. ${ }^{30}$ A survey from Brazil reported that $15.2 \%$ of nurses perceived severe work stress. ${ }^{31}$ A major aspect of burnout, work stress positively correlated with "intention to resign". 32 Recently, a survey has confirmed that high rates of nursing turnover indirectly stress those who continue. ${ }^{33}$ Thus, the stability of nursing teams is a widespread matter of contention. Conversely, job satisfaction was considered as the strongest predictor of nurses' retention. Forfeiture of nurses could be potentially decreased by enhancing their job satisfaction. ${ }^{8,34,35}$ Recent studies conclude that? nearly early $40 \%$ of nurses in Hong Kong ${ }^{36}$ and $56 \%$ in mainland China ${ }^{37}$ have attested to job dissatisfaction. This heeds a warning for nursing managers and policymakers to concern themselves with addressing the issues of job satisfaction, especially with the looming shortage of nurses. Despite strong suggestions related to the common reasons and possible remedies, the turnover trends continue to still flux. Due to the identified causative factors of nursing scarcity globally, turnover warrants intense investigation with a deeper perspective to acquire insights and to address associated aggravating issues. Although we found a good body of literature investigate the turnover yet, even methodological limitations of the research were minimize, it might be challenging to produce data that were generalizable and useful globally, especially in Saudi Arabia context. This study explores a deeper and comprehensive psychological perspective of turnover intention by delving into issues from a wider group of foreign nurses working in Kingdom of Saudi Arabia.

\section{Methods}

\section{Study design and participant characteristics}

A quantitative-based cross-sectional descriptive study design that use survey data to make statistical inferences about foreign nurse turnover in Saudi, was employed using convenience sampling to recruit 639 study participants. The participants were as follows Indian, Filipino, Egyptian Sudan, Jordanian, Malaysian, and Pakistani. The target population was foreign nurses working for more than six months in eight tertiary hospitals under the Ministry of Health, Saudi Arabia. Consenting respondents, meeting inclusion criteria, answered questionnaires at their convenience.

\section{Criteria of inclusion and exclusion}

Foreign nurses with more than six months of experience working in $\mathrm{MOH}$ hospitals were considered for the study. Nurses of Saudi nationality and foreign nurses having less than six months' service or employed in private hospitals were excluded.

\section{Tools of the study}

The instrument was used to answer the research objectives is an online self-reported questionnaire explicitly developed by the investigators based on questionnaires from earlier studies and extensive literature on nursing turnover. ${ }^{7,8,20,21}$ The instrument reliability measured using Cronbach's alpha was 0.97 . The final scale consisted of nine dimensions explore the factors that attribute to turnover marked using a 5-point Likert scale (5 points: strongly agree to 1 point: strongly disagree) in two parts. The first part involved demographics data (including age, gender, professional qualification, experience in years, nurse position and nationality); the second part self-reported evaluation of the staff to identify factors influencing the termination and nurse's area of concern, consist of forty-nine sub-questions under the main study dimensions including the intention to leave or stay, professional growth and development, leadership style, management, wage and benefit, workload, interpersonal relationship, hospital facilities, house and services facilities, and foodservice. The online tool consisted of two sections and fifty-seven items overall. A pilot study carried out with 18 nurses, which was excluded from the final study sample, involved a panel of four experts in nursing, leadership, education, quality, and primary nursing. Their recommendations were taken into consideration. The pilot aimed to test the feasibility and clarity of $\square$ the instrument intended to be used on a larger scale. It also aided the investigators to figure out the time needed to complete the $\square$ survey, which was $15 \mathrm{~min}$. Post this; the questionnaire was authorized and made operable in its final adapted form as an online survey. Informed consent for participation was obtained using the online survey interface through a statement that informed the par- 
ticipant that their response assumed that they provided informed consent. To guarantee data confidentiality, personal identifiers were not collected.

\section{Study procedures}

The Regional Bioethics Committee of the General Directorate of Health Affairs, Hail region, approved the study. Communication was established with ten hospitals under the Ministry of Health $(\mathrm{n}=10)$; eight positively replied to participate, yielding an $80 \%$ response rate. The consent for participation was by completion and submission of the survey. The data was collected by the developed Google form online survey sent to staff meets the inclusion criteria through WhatsApp. Anonymity, confidentiality of information and voluntary participation in the study were emphasized in the WhatsApp message. The data was collected from May 30 to June 15,2020 resulting in 639 completed responses.

\section{Statistical analysis}

Categorical data was presented by frequency with percentage, while continuous data was portrayed using mean with standard deviation. Association with demographic variables were tested by using independent $t$-test and ANOVA. All the analysis were done by using SPSS $23.0 \mathrm{v}$. A p-value less than 0.05 was deemed significant.

\section{Results}

Table 1 established that the nursing population was predominantly female $(622 ; 97.3 \%)$, revolving mostly around the ages 20 40 years (20-30 years) $47.6 \%$ and $31-40$ years $(40.1 \%)$. The majority held a bachelor's degree $(528 ; 82.6 \%)$, had 5-9 years of experience $(269 ; 42.1 \%)$ and were of the staff nurse cadre $(462 ; 72.3 \%)$. The majority of nurses working in $\mathrm{MOH}$ were found to be Indian (313; 49\%) and Filipino (280; 43.8\%).

The questionnaire responses were scored from "strongly agree" at 5 points to "strongly disagree" at 1 , with the mean and standard deviation values accordingly calculated (Table 2). High mean scores under professional growth and development, marked the importance of encouragement and improvement with "active staff development or continuing education" showing highest mean score (4.1 \pm 0.7$)$. Most participants agreed that the leadership styles were creditable; all the questions having a mean of $3.6 \pm 0.9$ or more, with "the nursing leadership is visible and accessible" rank-

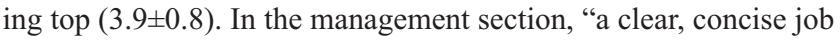
description" ranked first (3.9 \pm 0.8 ), while many disagreed with "enough registered nurses providing quality patient care" $(3.3 \pm 1.1)$. Overall response, however, showed a positive management impact. Regarding wages and benefits, many respondents did not agree that "extra work is acknowledged with monetary incentive" (3.1 \pm 1.2$)$, but majority agreed with other questions, all showing a mean of $3.6 \pm 1.0 / 1.1$, implying a strong effect on the staff turnover. The workload factors leveraged a negative impact with a high mean $(3.7 \pm 0.8)$ of respondents agreeing that "the amount of work interferes with how well it is done" coupled with low agreement scores for other questions, thus, reinforcing the heavy workloads. Interpersonal relationships were found to be satisfactory with favorable mean scores, with the top ranked being "I have a chance maintaining interpersonal relationship, enjoying leisure time with proper distribution working hours and off." (3.6 \pm 0.9$)$. The housing facilities and services showed disheartening scores, highest mean being $3.6 \pm 0.9$ for "There is reasonable privilege to go out for recreation" and "The staff are given option to take either raw or cooked food supply" and lowest being $2.8 \pm 1.3$ for "There is variety and balance diet food items provided". The hospital facilities were found less than adequate with only few agreeable scores, "There is available system to contact on-call staff and physicians" having the highest mean of $3.3 \pm 1.1$. The intent to stay and turnover intention was established to be low wherein only a mean of $2.9 \pm 1.1$ agreed that "Under no circumstance, I would probably be leaving this organization before my retirement age" while $3.4 \pm 1.1$ conceded that "I plan to stay in this organization for as long as I am needed".

A comprehensive view of the various factor categories and significant associations with the demographic variables (Table 3) showed that the age of the nursing population did not have any significant association with any of the factor groups. The female gender of the nursing staff had a statistically significant relationship with leadership style and turnover intent, and a very high significance $(p<0.001)$ when associated with the management. Diploma holders had a significant influence on all the factor groups except the workload. There was a strong association $(p<0.001)$ between them and wage - benefits and an intent to stay. The relationship between the management and nurses with higher education showed statistical significance, like hospital facilities with bachelor's degree holders. Nurses with 1-4 years of experience had a statistically significant association with leadership style, management, wage and benefits, interpersonal relationships, and turn-over intention. Those with $>10$ years under the belt were significantly

Table 1. Demographic characteristics (n=639).

\begin{tabular}{|c|c|c|}
\hline & Number & Percentage \\
\hline 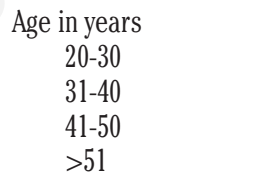 & $\begin{array}{l}304 \\
256 \\
65 \\
14\end{array}$ & $\begin{array}{l}47.6 \\
40.1 \\
10.2 \\
2.2\end{array}$ \\
\hline $\begin{array}{l}\text { Gender } \\
\text { Male } \\
\text { Female } \\
\end{array}$ & $\begin{array}{c}17 \\
622\end{array}$ & $\begin{array}{c}2.7 \\
97.3\end{array}$ \\
\hline $\begin{array}{l}\text { Qualification } \\
\text { Diploma } \\
\text { Bachelor } \\
\text { Higher education } \\
\text { Post-graduate }\end{array}$ & $\begin{array}{c}89 \\
528 \\
7 \\
15\end{array}$ & $\begin{array}{l}13.9 \\
82.6 \\
1.1 \\
2.3\end{array}$ \\
\hline $\begin{array}{l}\text { Years of experience } \\
\qquad \begin{array}{c}1-4 \\
5-9 \\
>10\end{array}\end{array}$ & & $\begin{array}{ll}202 & 31.6 \\
269 & 42.1 \\
168 & 26.3\end{array}$ \\
\hline $\begin{array}{l}\text { Nursing position } \\
\text { Charge nurse } \\
\text { Head nurse } \\
\text { Nurse supervisor } \\
\text { Staff nurse }\end{array}$ & $\begin{array}{c}102 \\
39 \\
35 \\
462\end{array}$ & $\begin{array}{c}16.0 \\
6.1 \\
5.5 \\
72.3\end{array}$ \\
\hline $\begin{array}{l}\text { Nationality } \\
\text { Egyptian } \\
\text { Filipino } \\
\text { Indian } \\
\text { Indonesian } \\
\text { Jordanian } \\
\text { Malaysian } \\
\text { Pakistani } \\
\text { Sudani } \\
\end{array}$ & $\begin{array}{c}9 \\
280 \\
313 \\
4 \\
2 \\
1 \\
1 \\
9\end{array}$ & $\begin{array}{c}1.4 \\
43.8 \\
49.0 \\
0.6 \\
0.3 \\
0.1 \\
0.1 \\
1.4 \\
\end{array}$ \\
\hline
\end{tabular}


Table 2. Response score.

\begin{tabular}{|c|c|c|c|}
\hline Items & & Mean score & SD \\
\hline No. & Professional growth and development & & \\
\hline 1 & Active staff development or continuing education & 4.1 & 0.7 \\
\hline 2 & Clinical opportunities and career advancement & 3.9 & 0.7 \\
\hline 3 & I received a proper guidance and suggestion for improvement whenever my work is not efficient enough Leadership style & 3.9 & 0.8 \\
\hline 4 & The nursing leadership is visible and accessible & 3.9 & 0.8 \\
\hline 5 & The chief nurse who has equal power and authority to other level of hospital executives & 3.8 & 0.9 \\
\hline 6 & I received too little acknowledgement from my superior & 3.6 & 0.9 \\
\hline 7 & Conflict from among the staff within the department and with others are dealt with professionally. & 3.7 & 0.9 \\
\hline \multirow[t]{2}{*}{8} & There is a support given to staff involve in any kind of complaint and investigation conducted to them & 3.6 & 0.9 \\
\hline & Management & & \\
\hline 9 & There are liaison personnel to take charge administrative matter & 3.6 & 0.9 \\
\hline 10 & Teamwork is observed between nurses and other members of health care team & 3.8 & 0.9 \\
\hline 11 & There is opportunity for staff nurses to participate in policy decision & 3.6 & 0.9 \\
\hline 12 & Work assignment is based on work experience and training & 3.6 & 0.9 \\
\hline 13 & A copy of Job description is a clear, concise and given to each staff & 3.9 & 0.8 \\
\hline 14 & Enough registered nurses to provide quality patient care & 3.3 & 1.1 \\
\hline 15 & Pull out to critical areas are applied to staff who have experience or underwent cross training. & 3.5 & 1.0 \\
\hline 16 & Administrative assignment can be declined and never forced & 3.6 & 0.9 \\
\hline \multirow[t]{2}{*}{17} & A clear philosophy of nursing that pervades the patient care environment. & 3.8 & 0.8 \\
\hline & Wage and benefits & & \\
\hline 18 & My income corresponds to the level of responsibility and demands of my job & 3.3 & 1.2 \\
\hline 19 & Extra work is acknowledged with monetary incentive & 3.1 & 1.2 \\
\hline 20 & The wage and benefit are on time & 3.6 & 1.1 \\
\hline 21 & My salary positively reflects the value of my work & 3.4 & 1.1 \\
\hline 22 & The vacation plan is fairly distributed according to policy & 3.6 & 1.0 \\
\hline 23 & Split vacation is allowed according to availability of staffing & 3.6 & 1.1 \\
\hline \multirow[t]{2}{*}{24} & Compensatory leave is allowed to be availed together with the annual vacation leave & 3.6 & 1.0 \\
\hline & Workload & & \\
\hline 25 & I can perform my tasks well because the workload is not heavy & 3.4 & 1.0 \\
\hline 26 & I work under a great deal of stress due to insufficient time to complete my tasks & 3.5 & 0.9 \\
\hline 27 & The amount of work interferes with how well it's gets done & 3.7 & 0.8 \\
\hline 28 & I spend too much time with office work & 3.3 & 0.9 \\
\hline 29 & 8 Hours shift gives me enough time to rest & 3.6 & 1.0 \\
\hline 30 & Extra on call duty is fairly distributed and given me time to attend to my personal stuffs & 3.4 & 0.9 \\
\hline \multirow[t]{2}{*}{31} & Duty schedule is accessible, flexible and any changes has prior notice & 3.6 & 0.9 \\
\hline & Interpersonal relationship & & \\
\hline 32 & I have a chance maintaining interpersonal relationship, enjoying leisure time with proper distribution working hours and off. & 3.6 & 0.9 \\
\hline 33 & I don't feel I have a benefit of my work. & 3.4 & 0.9 \\
\hline 34 & Some relatives think that we are not able to provide optimal medical or patient care & 3.4 & 1.0 \\
\hline \multirow[t]{2}{*}{35} & The staff home and work life are given importance & 3.5 & 1.0 \\
\hline & Housing facilities and services & & \\
\hline 36 & The staff accommodation is clean and safe for all employees & 3.2 & 1.2 \\
\hline 37 & Appropriate amenities are available and adequate & 3.3 & 1.0 \\
\hline 38 & There is reasonable privilege to go out for recreation & 3.6 & 0.9 \\
\hline 39 & The staff are given option to take either raw or cooked food supply & 3.6 & 1.0 \\
\hline 40 & The food supply is fresh and adequate & 3.3 & 1.1 \\
\hline 41 & The food serve to us per meal is on time and provide us adequate time to collect our food & 3.3 & 1.1 \\
\hline 42 & There is variety and balance diet food items provided 2.8 & 1.3 & \\
\hline \multirow[t]{2}{*}{43} & The Food server or food supply staff behaviour reflects respect to all employees & 2.9 & 1.2 \\
\hline & Hospital facilities & & \\
\hline 44 & There is accessible Wi-Fi for electronic personnel transaction & 2.8 & 1.2 \\
\hline 45 & Assistance is provided to access personnel digital filing & 3.2 & 1.1 \\
\hline \multirow[t]{2}{*}{46} & There is available system to contact on call staff and physicians & 3.3 & 1.1 \\
\hline & Intent to stay and turn-over intention & & \\
\hline 47 & I plan to stay in this organization for as long as I am needed & 3.4 & 1.1 \\
\hline 48 & Under no circumstance, I would probably be leaving this organization before my retirement age & 2.9 & 1.1 \\
\hline
\end{tabular}


associated with management, wage and benefits, and turnover intention. Those with 5-9 years of experience had no statistically significant relationships. Only professional growth and development were affected significantly by the nursing position, mainly charge nurse.

\section{Discussion}

The primary aim of this research is to provide an overview of the factors influencing nursing turnover in the $\mathrm{MOH}$ hospitals of Saudi Arabia, especially in expatriates. Many studies have been conducted in private and $\mathrm{MOH}$ hospitals regarding the rates, cause and consequences of such an anomaly, but there is a paucity of studies that explored turnover intention in nurses of foreign nationality. ${ }^{7,38}$ The data collected has been analyzed in 9 dimensions, calculating statistical associations and influence of these factors across various demographic parameters of respondents.

The nursing workforce was found predominantly female, analogous to most studies with nurses working in Saudi hospitals. ${ }^{38,39}$ The age of the nurses was mostly between 20 and 40, majority having Bachelor's degree and working in Staff nurse cadre, similar to studies by Kaddourah et al. and Saquib et al. ${ }^{8,39}$ In contrast to the $<5$ years tenure seen in these studies, a 5-9 year work experience was found common here. The multinational nursing population was dominated by Indian nurses, closely followed by Filipino,

Table 3. Association with demographic variables.

\begin{tabular}{|c|c|c|c|c|c|c|c|c|c|c|c|c|c|c|c|c|c|c|}
\hline \multirow[t]{2}{*}{$\begin{array}{l}\text { Demographic } \\
\text { features }\end{array}$} & \multicolumn{2}{|c|}{$\begin{array}{l}\text { Professional } \\
\text { growth and } \\
\text { development }\end{array}$} & \multicolumn{2}{|c|}{$\begin{array}{l}\text { Leadership } \\
\text { style }\end{array}$} & \multicolumn{2}{|c|}{ Management } & \multicolumn{2}{|c|}{$\begin{array}{l}\text { Wage and } \\
\text { benefits }\end{array}$} & \multicolumn{2}{|c|}{ Workload } & \multicolumn{2}{|c|}{$\begin{array}{l}\text { Interpersonal } \\
\text { relationship }\end{array}$} & \multicolumn{2}{|c|}{$\begin{array}{c}\text { Housing facilities } \\
\text { and Services }\end{array}$} & \multicolumn{2}{|c|}{$\begin{array}{l}\text { Hospital } \\
\text { facilities }\end{array}$} & \multicolumn{2}{|c|}{$\begin{array}{l}\text { Intent to stay } \\
\text { and turn-over } \\
\text { intention }\end{array}$} \\
\hline & $\begin{array}{l}\text { Mean } \\
\text { (SD) }\end{array}$ & p-value & $\begin{array}{l}\text { Mean } \\
\text { (SD) }\end{array}$ & p-value & $\begin{array}{l}\text { Mean } \\
\text { (SD) }\end{array}$ & p-value & $\begin{array}{l}\text { Mean } \\
(\mathrm{SD})\end{array}$ & $\mathrm{p}$-value & $\begin{array}{l}\text { Mean } \\
\text { (SD) }\end{array}$ & p-value & $\begin{array}{l}\text { Mean } \\
\text { (SD) }\end{array}$ & p-value & $\begin{array}{l}\text { Mean } \\
\text { (SD) }\end{array}$ & p-value & $\begin{array}{l}\text { Mean } \\
\text { (SD) }\end{array}$ & p-value & $\begin{array}{l}\text { Mean } \\
\text { (SD) }\end{array}$ & p-value \\
\hline \multicolumn{19}{|l|}{ Age in yrs } \\
\hline $20-30$ & $3.7(1.0)$ & 0.425 & $3.5(0.9)$ & 0.318 & $3.5(0.9)$ & 0.490 & $3.2(0.9)$ & 0.234 & $3.3(0.8)$ & 0.811 & $3.2(0.8)$ & 0.224 & $3.1(0.8)$ & 0.858 & $3.1(0.9)$ & 0.757 & $3.1(1.1)$ & 0.082 \\
\hline $31-40$ & $4.0(0.6)$ & & $3.7(0.6)$ & & $3.7(0.7)$ & & $3.5(0.9)$ & & $3.5(0.6)$ & & $3.5(0.7)$ & & $3.3(0.8)$ & & $3.1(1.0)$ & & $3.2(0.9)$ & \\
\hline $41-50$ & $3.9(0.7)$ & & $3.6(0.7)$ & & $3.6(0.8)$ & & $3.4(0.9)$ & & $3.5(0.7)$ & & $3.4(0.8)$ & & $3.2(0.9)$ & & $3.1(1.0)$ & & $3.0(1.1)$ & \\
\hline$>51$ & $4.1(0.5)$ & & $3.7(0.7)$ & & $3.7(0.7)$ & & $3.6(0.6)$ & & $3.5(0.7)$ & & $3.5(0.7)$ & & $3.3(0.7)$ & & $3.2(0.9)$ & & $3.4(0.9)$ & \\
\hline \multicolumn{19}{|l|}{ Gender } \\
\hline Male & $3.9(0.7)$ & 0.362 & $3.7(0.7)$ & $0.024^{*}$ & $3.7(0.7)$ & $<0.001^{*}$ & $3.5(0.9)$ & 0.307 & $3.5(0.7)$ & 0.452 & $3.5(0.8)$ & 0.693 & $3.3(0.8)$ & 0.151 & $3.1(1.0)$ & 0.081 & $3.2(1.0)$ & $0.042 *$ \\
\hline Female & $3.8(0.9)$ & & $3.3(0.8)^{*}$ & & $3.0(0.8)^{*}$ & & $3.3(0.9)$ & & $3.6(0.9)$ & & $3.5(0.7)$ & & $2.9(0.7)$ & & $2.7(1.0)$ & & $2.6(1.0)^{*}$ & \\
\hline \multicolumn{19}{|c|}{ Qualification } \\
\hline Diploma & $3.9(0.6)^{*}$ & $0.008 *$ & $3.7(0.6)^{*}$ & $0.006 *$ & $3.6(0.7)^{*}$ & $0.004 *$ & $3.4(0.9)^{*}$ & $<0.001 * *$ & $3.5(0.7)$ & 0.176 & $3.4(0.7)^{*}$ & $0.002 *$ & $3.2(0.8)^{*}$ & $0.019 *$ & $3.0(0.9)^{*}$ & $0.005^{*}$ & $3.1(1.0)^{*}$ & $<0.001^{* *}$ \\
\hline Bachelor & $4.1(0.7)$ & & $3.9(0.8)$ & & $3.9(0.8)$ & & $3.9(0.9)$ & & $3.6(0.8)$ & & $3.7(0.9)$ & & $3.4(1.0)$ & & $3.3(1.2)^{*}$ & & $3.4(1.1)$ & \\
\hline Higher education & $4.3(0.7)$ & & $3.9(0.7)$ & & $3.6(0.9)^{*}$ & & $3.9(0.9)$ & & $3.7(0.9)$ & & $3.9(0.7)$ & & $3.8(0.8)$ & & $3.8(0.8)$ & & $4.0(0.9)$ & \\
\hline Post- graduate & $4.3(0.7)$ & & $4.0(0.6)$ & & $3.9(0.6)$ & & $3.6(0.9)$ & & $3.6(0.7)$ & & $3.5(0.7)^{*}$ & & $3.6(0.6$ & & $3.6(0.9)$ & & $3.6(0.8)$ & \\
\hline \multicolumn{19}{|c|}{ Years of experience } \\
\hline $1-4$ & $3.9(0.6)$ & 0.425 & $3.6(0.7)^{*}$ & $0.033^{*}$ & $3.6(0.7)^{*}$ & $0.031 *$ & $3.4(0.8)^{*}$ & $0.004^{*}$ & $3.4(0.6)$ & 0.059 & $3.3(0.7)^{*}$ & $0.001^{*}$ & $3.2(0.7)$ & 0.266 & $3.0(0.9)$ & 0.568 & $3.1(0.9)^{*}$ & $0.002 *$ \\
\hline $5-9$ & $4.0(0.7)$ & & $3.8(0.7)$ & & $3.8(0.7)$ & & $3.6(0.8)$ & & $3.6(0.7)$ & & $3.6(0.8)$ & & $3.3(0.9)$ & & $3.1(1.1)$ & & $3.3(0.9)$ & \\
\hline$>10$ & $3.9(0.7)$ & & $3.7(0.7)$ & & $3.6(0.8)^{*}$ & & $3.4(0.9)^{*}$ & & $3.5(0.7)$ & & $3.5(0.7$ & & $3.2(0.8)$ & & $3.1(1.0)$ & & $3.0(1.1)^{*}$ & \\
\hline \multicolumn{19}{|c|}{ Nursing position } \\
\hline Charge nurse & $3.8(0.7)^{*}$ & $0.009 *$ & $3.6(0.8)$ & 0.689 & $3.6(0.8)$ & 0.850 & $3.4(0.9)$ & 0.246 & $3.5(0.7)$ & 0.872 & $3.4(0.7)$ & 0.106 & $3.2(0.8)$ & 0.889 & $3.1(0.9)$ & 0.295 & $3.2(1.0)$ & 0.544 \\
\hline Head nurse & $3.9(0.6)$ & & $3.6(0.7)$ & & $3.6(0.7)$ & & $3.3(0.9)$ & & $3.5(0.7)$ & & $3.3(0.8)$ & & $3.3(0.8)$ & & $3.2(0.9)$ & & $3.1(1.0)$ & \\
\hline Nurse supervisor & $4.3(0.5)$ & & $3.8(0.7)$ & & $3.6(0.7)$ & & $3.2(0.6)$ & & $3.5(0.5)$ & & $3.3(0.5)$ & & $3.2(0.7)$ & & $3.4(0.9)$ & & $2.9(1.1)$ & \\
\hline Staff nurse & $4.0(0.7)$ & & $3.7(0.7)$ & & $3.7(0.6)$ & & $3.5(0.9)$ & & $3.5(0.7)$ & & $3.5(0.8)$ & & $3.3(0.8)$ & & $3.0(1.0)$ & & $3.2(1.0)$ & \\
\hline
\end{tabular}

*Statistically significant.

Table 4. Recommendation for future research on nursing turnover.

\begin{tabular}{ll}
\hline Area of research & Recommendation \\
Methodological & Long-term follow up needed \\
& Increase sample sizes \\
& Use Representative sample \\
& Intervention studies should be performed \\
& Integrate cultural differences and challenges facing nursing foreigners in future studies \\
& Future studies advised using another standpoint by focusing on nurses employed for an extended period and what \\
& kept them remain in their specialization
\end{tabular}


which is similar to Albougami et al. and Saquib et al. ${ }^{39,40}$ In contrast, the study by Kaddourah had a higher number of Filipino nurses. ${ }^{8}$

Agreement scores evaluated by a questionnaire spanning nine sections charted the views of the participants on the various factors that can be considered influencing their turnover intention. Professional growth and development were found to the most propitious incentives considering long term employment. A study by $\mathrm{Lu}$ et al. on job satisfaction of nurses elicited a poor satisfaction in this arena, insinuating a lack thereof to be a criterion for increasing nursing turnover, especially in expatriate nurses. ${ }^{41}$ Leadership styles and a management with clear job descriptions and adequate staff numbers for rotation have a vital influence on the nurses intention to stay as seen in previous studies. ${ }^{38,42,43}$ The findings in this study reflected a positive leadership and management experience, as compared to similar studies, where the satisfaction with leadership styles and management were not found acceptable. ${ }^{41,44,45}$

The wages and benefits conferred invoked a lukewarm response, with a relatively lower mean agreeing to their adequacy. Many studies have emphasized this factor, showing a similar dissatisfaction in nurses working internationally. ${ }^{41,44,46,47}$ Although financial incentives alone do not significantly influence long-term job satisfaction, ${ }^{48}$ they form a major driving force in expatriate nurses. A study by Aljohani and Alomari decreed low salary as the top cause for turnover in Filipino nurses. ${ }^{7}$ The current study reveals a very strong association between wages and nursing qualification, especially in diploma holders and with working experience, those with $<5$ years and $>10$ years, implying the lack of satisfactory wage bracket in these demographic groups to be a factor influencing turnover intent, corroborating previous studies' findings. ${ }^{8,44,49}$ The $\mathrm{MOH}$ decision-makers must explore constructive options in terms of mutually profitable financial packages if nurses' retention is to be attained.

A shortage of staff with ubiquitous emergency situations makes for an increased workload as hospitals ask nurses to work extra hours. ${ }^{46}$ Nurses are under constant pressure influencing work quality and stress levels. This can cause early burnouts, depression and job dissatisfaction especially with the nurses being far away from their home countries, leading to increased turnover. ${ }^{41,50}$ Interpersonal relationships with colleagues and superiors can form a strong impetus to stay on. Interdisciplinary teamwork and importance to home and work life are important factors influencing nurse's intention to stay. ${ }^{45,51}$

Housing facilities and services are a key factor in nurses' intent to stay. The results of the current study reinforce the findings of preceding studies that argued poor food quality, inferior accommodation and middling services as a further cause of turnover among expatriate nurses. $7,38,45$ Strategies to improve this by providing improved housing facilities and services like gym area, expanding scope of house matrons' responsibilities and professional hospitality training, providing supportive services to temporary nurses, and other such conveniences must be duly considered to improve the home life of the working nurses.

The hospital environment is the cornerstone of job satisfaction forming a core influence in turnover intention and intention to stay. A positive work environment encourages nurses to implement their full scope of practice and qualifications into patient care. ${ }^{41,45}$ The dissent with the hospital facilities, policies and communication systems in this study reflect findings from similar studies both within Saudi Arabia and internationally. 7,38,44,46,52

Organizational commitment in the form of intent to stay and turnover intention, was found to be low in this study, supporting findings in earlier documentation. ${ }^{46,53,54}$ This occurrence could be likely due to the cultural differences that impact non-Saudi nurses' values, beliefs, and behaviors in the workplace, an inability to adjust inducing an intent to resign, along with other pertinent factors. Nurses' demographics, including gender, educational attainment, wages, years of experience and nationality were observed to be determinants of nurse turnover and turnover intention. ${ }^{41,42,46,55,56}$ The associations formed when these are crossed with the 9 dimensions can indicate areas that significantly affect turnover intention. Older literature described younger nurses to have higher level of turnover intention and age to be positively associated with intent to stay. ${ }^{62,63}$ In contrast, ${ }^{60}$ contended that age had no effects on turnover intention. The present study also did not encounter any association between age and factors influencing turnover intention across the 9 sections.

Contrary to Almaki et al., 48 the study found females to have significant association with turnover intent and organisational commitment, and also in relationships with management and leadership styles similar to previous findings. ${ }^{42,43}$

Nurses with diplomas showed a significant association to almost all the factors influencing commitment to stay, contrary to Almaki et al., ${ }^{48}$ who established that respondents with an associate degree were more likely to indicate turnover intention. Nurses with higher education and those with post graduate degrees were significantly associated to management issues and interpersonal relationships respectively, although there are no similar studies to show the effect of nursing qualifications on these specific factors influencing turnover intention.

Staff with a work experience of less than 5 years had significant relationships with the leadership styles, management functions, wage and benefits aspect, interpersonal relationships and commitment to the organization, similar to findings of studies by Ayalew et al. ${ }^{45}$ which established that turnover intentions peaked among nurses with two to five years of experience. Labrague et al., ${ }^{44}$ also communicated that inverse relationships may exist between the nurse's years of work experience and turnover intentions although the present study confers that nurses with work experience greater than 10 years may show greater associations to management, wage and commitment related factors affecting intent to stay.

Studies to elicit associations between demographics and nursing turnover are many with varying results. Some studies have highlighted associations between age, experience and work tenure in an organization, and the intention to leave the organization, ${ }^{57,58}$ while others have found advanced age and longer job tenure to be a reason to leave jobs. ${ }^{59}$ Almalki et al ${ }^{48}$ established that only four demographic variables, gender, dependent adults, positional tenure and payment per month, had strong relationships with turnover intention. However the current study shows a broader view of the factors involved in nursing turnover intention in expatriate nurses, demonstrating more detailed associations between demographic variables and individual factors.

\section{Limitations}

A limitation of this study was potential bias and misinterpretation being based on self-reports. Also, convenience sampling method limits this research to expatriate nurses in the $\mathrm{MOH}$ and cannot be used to make generalized policies regarding nursing population as a whole. Despite these, the strength of this study lies in the investigation of the nurses' unique perspectives on their intent to resign, using a thoughtful questionnaire with myriad factors allowing a comprehensive understanding of the issues and problems provoking intention to leave. 


\section{Suggestions for future research}

A cross-sectional design can limit observations of change over time. Longitudinal and experimental studies could be considered to link participants at different time points and enable monitoring of actual attrition against turnover intention with a focus on the influence of nurse turnover on cost as well as patient outcomes (Table 4). A series of comparative studies, comparing expatriate nurses to other non- Saudi health professionals in the $\mathrm{MOH}$ and Primary Health Care (PHC) or private nurses to $\mathrm{MOH}$ nurses may deliver determinants of turnover intention of nursing personnel.

\section{Conclusions}

The challenges and transformations in the Saudi healthcare system especially $\mathrm{MOH}$, demand astute navigation in identifying and addressing requirements of nurses, as they represent the quorum of the country's healthcare manpower. Wage benefits and workload factors were found to be the most significant cause. The influence of factors such as inadequate housing and hospital facilities are longstanding contentions that have not been sufficiently rectified. The abundance of Indian and Filipino nurses, along with others, may face extensive difficulties to adapt to cultural differences. Organizational commitment must be improved with creditable and profitable strategies such as culture induction and enticing incentives, or a longer contract indicating security in the job. Maintaining and enhancing strengths such as professional growth and development is also essential. Review the existing policies has become urgent need to improve nurses working condition. Programs for learning, knowledge enhancement, training and development should be contemplated. Sustaining a healthy nursing force is crucial to enhance performance, productivity and promotion of safe nursing care.

\section{Implications to nursing management}

Nursing administrators are central to policy setting and implementation, capable of improving job engagement. respecting propensity for quality contribution, envisaging need for incentives and other retaining strategies. In the fast- developing global healthcare scenario, the constant evaluation and re-evaluation of the requirements for nurses of foreign nationality to stay working in Saudi is paramount. Hospital leaders need to develop strategies and policies that will help mitigate foreign nurse turnover.

Nursing administrators are vital to policy development and implementation, respecting propensity for quality contribution, envisaging need for incentives and other retaining strategies. In the fast- developing global healthcare environment, the constant valuation and re-evaluation of the requirements of nurses of foreign nationality is imperative to determine and address the needs of all parties concerned.
Correspondence: Nashi Masnad Alreshidi, Nursing Administration, Ministry of Health, Hail Region, Health Affairs, Governmental Complex, Hail City, Saudi Arabia.

Tel.+966548183321. E- mail: nmalreshidi@moh.gov.sa

Key words: Staff turnover; foreign nurses turnover; turnover behavior; healthcare cost; Saudi Arabia.

Acknowledgements: A sincere thank you is extended to all Registered Nurses who participated in this study and assisted to make this study a reality.

Conflict of interest: The authors declare that they have no competing interests, and all authors confirm accuracy.

Funding: This research did not receive any specific grant from funding agencies in the public, commercial, or not-for-profit sectors.

Ethics approval and consent to participate: This study was reviewed and approved by the Regional Bioethics Committee of the General Directorate of Health Affairs, Hail region, with the approval number 2020/14 dated March 24, 2020. Sufficient online information was provided to the participants, and a clear objective that will guide them in making an informed decision in participating in the study. The participants were formally assured of identity confidentiality.

Availability of data and materials: The data used to support the findings of this study are available from the corresponding author upon request.

Received for publication: 30 September 2020.

Accepted for publication: 12 December 2020

oCopyright: the Author(s), 2021

Licensee PAGEPress, Italy

Journal of Public Health Research 2021;10:1971

doi:10.4081/jphr.2021.1971

This work is licensed under a Creative Commons Attribution NonCommercial 4.0 License (CC BY-NC 4.0).

\section{References}

1. Hayes LJ, O'Brien-Pallas L, Duffield C, et al. Nurse turnover. A literature review. Int J Nurs Stud 2006; 43:237-63.

2. Baumann A. Impact of turnover and the benefit of stability. Int Nurs Rev 2010;38:167-79.

3. Hayes LJ, O'Brien-Pallas L, Duffield C, et al. Nurse turnover: a literature review - an update. Int J Nurs Stud 2012;49:887905.

4. Duffield CM, Roche MA, Homer C, et al. A comparative review of nurse turnover rates and costs across countries. J Adv Nurs 2014;70:2703-12.

5. Al-Maaitah R, Shokeh D. The nursing workforce in Jordan: A policy oriented approach. Jordan Nursing Council; 2009.

6. Li Y, Jones CB. A literature review of nursing turnover costs. J Nurs Manag 2013;21:405-18.

7. Aljohani KA, Alomari O. Turnover among Filipino nurses in Ministry of Health hospitals in Saudi Arabia: causes and recommendations for improvement. Ann Saudi Med 2018;38:140-2.

8. Kaddourah B, Abu-Shaheen AK, Al-Tannir M. Quality of nursing work life and turnover intention among nurses of tertiary care hospitals in Riyadh: a cross-sectional survey. BMC Nurs 


\section{8;17:43.}

9. Baptiste M. Workplace discrimination: An additional stressor for internationally educated nurses. Online J Issues Nurs 2015;20:8.

10. International Council of Nurses. The global nursing shortage: priority areas for intervention. Geneva; 2006.

11. OECD. Health at a Glance 2013: OECD Indicators. Paris: OECD Publishing; 2013. Available from: https://www.oecd.org/els/health-systems/Health-at-a-Glance2013.pdf

12. Victora CG, Barreto ML, Leal MC, et al. Health conditions and health-policy innovations in Brazil: the way forward. Lancet 2011;377:2042-53.

13. Oliveira D, Griep R, Portela LF, Rotengerg L. Intention to leave profession, psychosocial environment and self-rated health among registered nurses from large hospitals in Brazil: a cross- sectional study. BMC Health Serv Res 2017;17:21.

14. Hasselhorn HM, Tackenberg P, Müller BH. Working conditions and intent to leave the profession among nursing staff in Europe. National Institute for Working Life; 2003.

15. Jian L, Galatsch M, Siegrist J, et al. Reward frustration at work and "intention to leave" the nursing profession - prospective results from the European longitudinal NEXT study. Int J Nurs Stud 2011;48:628-35.

16. Holanda FL, Cunha ICKO. Time of permanence of nurses at a school-hospital and expenses related to admission, resignation and hiring of a new professional. Rev Lat Am Enfermagem 2005; $13: 642-7$

17. Price JL, Mueller CW. A causal model of turnover for nurses. Acad Manage J 1981;24:543-65.

18. Cortese CG. Predictors of critical care nurses' intention to leave the unit, the hospital, and the nursing profession. Open Nurs J 2012;2:311-26.

19. Van den Heede K, Florquin M, Bruyneel L, et al. Effective strategies for nurse retention in acute hospitals: a mixed method study. Int J Nurs Stud 2013;50:185-94.

20. Hasselhorn HM, Tackenberg P, Muller BH, et al. Nursing in Europe: "intention to leave" the nursing profession. Stockholm: NEXT Study Group; 2005. p. 2-79.

21. Flinkman M, Leino-Kilpi H, Salantera SM. Nurses' "intention to leave" the profession: integrative review. J Adv Nurs 2010;66:1422-34.

22. Chan MF, Leong SM, Luk AL, et al. Exploring the profiles of nurses' job satisfaction in Macau: results of a cluster analysis. J Clin Nurs 2009;19:470-8.

23. Araújo TM, Karasek R. Validity and reliability of the job content questionnaire in formal and informal jobs in Brazil. Scand J Work Environ Health 2008;6:52-9.

24. Siegrist J. Adverse health effects of high-effort/low-reward conditions. J Occup Health Psychol 1996;1:27-41.

25. Krausz M, Koslowsky M, Shalom N. Predictors of intentions to leave the ward, the hospital, and the nursing profession: a longitudinal study. J Organiz Behav 1995;16:277-88.

26. Morrell K. Towards a typology of nursing turn-over: the role of shocks in nurses' decisions to leave. J Adv Nurs 2005;49:315-22.

27. Lim J, Bogossian F, Ahern K. Stress and coping in Australian nurses: a systematic review. Int Nurs Rev 2010;57:22-31.

28. Khamisa N, Peltzer K, Ilic D, Oldenburg B. Work related stress, burnout, job satisfaction and general health of nurses: A follow-up study. Int J Nurs Pract 2016;22:538-45.

29. Dagget T, Molla A, Belachew T. Job related stress among nurses working in Jimma Zone public hospitals, South West
Ethiopia: across sectional study. BMC Nurs 2016;15:39.

30. Hooper C, Craig J, Janvrin DR, et al. Compassion satisfaction, burnout, and compassion fatigue among emergency nurses compared with nurses in other selected inpatient specialties. J Emerg Nurs 2010;36:420-7.

31. Negeliskii C, Lautert L. Occupational stress and work capacity ofnurses of a hospital group. Rev Lat Am Enfermagem 2011;19:606-13.

32. Paille P. Perceived stressful work, citizenship behavior and "intention to leave" the organization in a high turnover environment: Examining the mediating role of job satisfaction. J Manag Res 2010;3:1-14.

33. Yang H, Lv J, Zhou X, et al. Validation of work pressure and associated factors influencing hospital nurse turnover: a crosssectional investigation in Shaanxi Province, China. BMC Health Serv Res 2017;17:112.

34. Ellenbecker CH, Porell FW, Samia L, et al. Predictors of home healthcare nurse retention. J Nurs Scholarsh 2008;40:151-60.

35. Al Maqbali MA. Factors that influence nurses job satisfaction: a literature review. J Nurs Manag 2015;22:30-7.

36. Cheung T, Yip PS. Depression, anxiety and symptoms of stress among hong kong nurses: a cross-sectional study. Int J Environ Res Public Health 2015;12:11072-100.

37. Lu M, Ruan H, Xing W, et al. Nurse burnout in China: a questionnaire survey on staffing, job satisfaction, and quality of care. J Nurs Manag 2015;23:440-7.

38. Falatah R, Salem OA. Nurse turnover in the Kingdom of Saudi Arabia: An integrative review. J Nurs Manag 2018;26:630-8.

39. Saquib J, Taleb M, AlMeimar R, et al. Job insecurity, fear of litigation, and mental health among expatriate nurses. Arch Environ Occup Health 2020;75:144-51.

40. Albougami AS, Alotaibi JS, Alsharari AF, et al. Cultural competence and perception of patient-centered care among nonMuslim expatriate nurses in Saudi Arabia: A cross sectional study. Pakistan J Med Heal Sci 2019;13:933-8.

41. Lu H, Zhao Y, While A. Job satisfaction among hospital nurses: A literature review. Int J Nurs Stud 2019;94:21-31.

42. Abualrub RF, Alghamdi MG. The impact of leadership styles on nurses' satisfaction and intention to stay among Saudi nurses. J Nurs Manag 2012;20:668-78.

43. Al-Yami M, Galdas P, Watson R. Leadership style and organisational commitment among nursing staff in Saudi Arabia. J Nurs Manag 2018;26:531-9.

44. Labrague LJ, Gloe DS, McEnroe DM, et al. Factors influencing turnover intention among registered nurses in Samar Philippines. Appl Nurs Res 2018;39:200-6.

45. Aljohani K. Nurses' job satisfaction: A multi-center study. Saudi J Health Sci 2019;8:167.

46. Ayalew F, Kols A, Kim Y-M, et al. Factors affecting turnover intention among nurses in Ethiopia. World Health Popul 2015;16:62-74.

47. Al-Dossary R, Vail J, Macfarlane F. Job satisfaction of nurses in a Saudi Arabian university teaching hospital: a cross-sectional study. Int Nurs Rev 2012;59:424-3.

48. Almalki MJ, FitzGerald G, Clark M. The relationship between quality of work life and turnover intention of primary health care nurses in Saudi Arabia. BMC Health Serv Res 2012;12:314

49. Zaghloul MS, Saquib J, AlMazrou A, et al. Mental health status of expatriate nurses in Northcentral Saudi Arabia. J Immigr Minor Heal 2019;6:1233-40.

50. Yasin YM, Al-Hamad A, Bélanger CH, et al. Expatriate health professionals in the Saudi Arabia private sector. Br J Health 
Care Manag 2017;23:176-85.

51. Labrague LJ, McEnroe-Petitte DM, Tsaras K, et al. Organizational commitment and turnover intention among rural nurses in the Philippines: Implications for nursing management. Int J Nurs Sci 2018;5:403-8.

52. Albougami AS, Almazan JU, Cruz JP, et al. Factors affecting nurses' intention to leave their current jobs in Saudi Arabia. Int J Health Sci 2020;14:33-40.

53. Alosaimi DN, Ahmad MM. The challenges of cultural competency among expatriate nurses working in kingdom of Saudi Arabia. Res Theor Nurs Pract 2016;30:302-9.

54. Al-Ahmadi H. Anticipated nurses' turnover in public hospitals in Saudi Arabia. Int J Hum Resour 2014;25:412-33.

55. Almalki M, Fitzgerald G, Clark M. The nursing profession in Saudi Arabia: An overview. Int Nurs Rev 2011;58:304-11.
56. Crossley CD, Bennett RJ, Jex SM, et al. Development of a global measure of job embeddedness and integration into a traditional model of voluntary turnover: Clarification to Crossley et al. (2007). J Appl Soc Psychol 2011;96:1316.

57. O'Brien-Pallas L, Murphy GT, Shamian J, et al. Impact and determinants of nurse turnover: A pan-Canadian study. J Nurs Manag 2010;18:1073-86.

58. Abubakar RA, Chauhan A, Kura KM. Relationship between perceived organizational politics, organizational trust, human resource management practices and turnover intention among Nigerian nurses. Manag Sci Lett 2014;4:2031-48.

59. Takase M, Teraoka S, Kousuke Y. Investigating the adequacy of the Competence Turnover Intention Model: How does nursing competence affect nurses' turnover intention? J Clin Nurs 2015;24:805-16. 